\title{
Identidade Visual de Museus de Arte Brasileiros: o contexto da cidade de São Paulo
}

\author{
Visual Identity of Brazilian Art Museums: the context of the city of São Paulo
}

\author{
PIAIA, Jade Samara; Doutora; FAU-USP / FAAL / Unicamp \\ jadepiaia@gmail.com \\ PFÜTZENREUTER, Edson do Prado; Doutor; Unicamp \\ edson.reuter@gmail.com
}

\section{Resumo}

Este artigo trata de uma pesquisa no campo da memória gráfica com foco na história da identidade visual de alguns dos importantes museus de Arte em São Paulo, Brasil, tais como a Pinacoteca, o Museu de Arte de São Paulo (Masp), o Museu de Arte Moderna de São Paulo (MAMSP) e o Museu de Arte Contemporânea (MAC-USP). A investigação acerca da memória gráfica destes museus justifica-se pela riqueza de seus materiais gráficos os quais podem revelar processos gráficos, profissionais e empresas atuantes na cidade de São Paulo em diferentes períodos, a partir de uma investigação das identidades construídas ao longo do último século. Métodos relacionados à pesquisa e análise de memória gráfica, utilizados para coleta, seleção, organização, fichamento e análise dos dados foram aplicados, cruzados e complementados com levantamentos de dados adicionais e relatos de história oral. Os resultados evidenciam algumas das principais mudanças visuais e gráficas que ocorreram nas identidades desses museus e chamam atenção para o contexto histórico e os profissionais gráficos envolvidos.

Palavras Chave: memória gráfica; identidade visual; museu de arte.

\begin{abstract}
This paper is about a research in the field of graphic memory with focus in the history of visual identity of some important Art Museums in São Paulo, Brazil, such as the Pinacoteca, the Museum of Art of São Paulo (Masp), the Museum of Modern Art of São Paulo (MAM-SP) and the Museum of Contemporary Art (MAC-USP). The graphic memory research of these museums are justified by the richness of their graphic materials which can reveal graphic processes, professionals and companies operating in the city of São Paulo at different periods, from a research on identities built along the last century. Methods related to graphic memory research and analysis were used for collection, selection, organization, annotations, and analysis of the data was applied, crossed and complemented with additional data surveys and reports from oral history. The results highlight some of the visual and graphic changes that occurred in these museums' identities, call attention to the historical context and the graphic professionals who worked on their development.
\end{abstract}

Keywords: graphic memory; visual identity; art museum. 


\section{Os museus de artes e o contexto dos museus paulistas}

Este estudo aborda museus de grande importância voltados às artes visuais instalados na cidade de São Paulo. Parte-se da definição de museu publicada pelo Instituto Brasileiro de Museus (Ibram) (2011), que por sua vez adota o conceito definidor expresso no Estatuto de Museus ${ }^{1}$, o qual estabelece:

Consideram-se museus, para os efeitos desta Lei, as instituições sem fins lucrativos que conservam, investigam, comunicam, interpretam e expõem, para fins de preservação, estudo, pesquisa, educação, contemplação e turismo, conjuntos e coleções de valor histórico, artístico, científico, técnico ou de qualquer outra natureza cultural, abertas ao público, a serviço da sociedade e de seu desenvolvimento. (...) (IBRAM, 2011, p. 15)

O corpus pesquisado compreende o ponto de vista geográfico e a tipologia do acervo, optando-se por museus situados em São Paulo e voltados às artes visuais, que se denominam de arte, ou com maior parte do acervo total de peças de arte. Influenciaram nessa definição o tempo de atividade do museu, a existência de um acervo de memória gráfica e a possibilidade de acesso e consulta a esse acervo. Diante do levantamento realizado foi considerado para pontuar o contexto paulistano de museus voltados às artes visuais a Pinacoteca do Estado de São Paulo, o Masp, o MAM-SP e o MAC-USP.

Cabe apontar de modo introdutório algumas referências da formação do contexto paulistano da arte e dos museus dedicados às artes. O primeiro museu do estado de São Paulo, o Museu Paulista, hoje conhecido como Museu do Ipiranga e vinculado à USP, foi fundado em 7 de setembro de 1895, na época como Museu de História Natural (MUSEU PAULISTA, s. d.). Seu acervo inicial contou com a doação de uma coleção particular do Coronel Joaquim Sertório ${ }^{2}$ e as coleções expostas pelo museu iam "de animais empalhados a mobiliários, não contemplando as artes plásticas como principal atração" (CINTRÃO, 2011, p. 23). O primeiro museu dedicado exclusivamente às artes no estado de São Paulo foi a Pinacoteca, fundada em 1905, que passou a funcionar em duas salas no andar superior do edifício do Liceu de Artes e Ofícios, a partir de uma doação de obras vindas do Museu Paulista. Manteve-se como o único museu de artes, segundo definição IBRAM (2011), até 1947, quando ocorre a fundação do Masp na sede dos Diários Associados por Assis Chateaubriand. Cabe ressaltar que esses não foram os únicos lugares que acolheram as artes na capital paulista no início do século XX.

Rejane Cintrão (2011) elenca alguns espaços institucionais que marcaram a cena cultural na cidade de São Paulo até a década de 1930. Além do Museu Paulista, foram citados o Liceu de Artes e Ofícios, fundado em 1874, que atuava como um centro de educação não-formal provedor de aulas e atividades artísticas, a Pinacoteca do Estado, fundada em 1905, e o Teatro Municipal, inaugurado em 1911, que recebeu a Semana de Arte Moderna, liderada por Mário de Andrade em fevereiro de 1922. Diversas exposições organizadas pela Pinacoteca ocorriam no Liceu, como as "I e II Exposições Brasileiras de Bellas-Artes (1911 e 1912), a Exposição de Arte Espanhola (1911) e a Exposição de Arte Francesa (1913), além de algumas mostras individuais, a exemplo da exposição de Pedro Alexandrino" (CINTRÃO, 2011, p. 83). A autora cita também algumas galerias de arte com importante atuação na cidade de São Paulo no início do século XX, como a Galeria Artística, a

\footnotetext{
${ }^{1}$ Promulgado pela Lei no 11.904, de 14 de janeiro de 2009 (BRASIL, 2009).

${ }^{2}$ Doação realizada pelo Conselheiro Francisco de Paula Mayrink que comprou a residência junto com os objetos e a coleção do Coronel Joaquim Sertório e a doou ao governo do Estado (CINTRÃO, 2011, p. 56).
} 
Galeria Jorge, a Galeria Blanchon e o Club Commercial (CINTRÃO, 2011).

Havia então uma movimentação cultural com exposições que se concentravam principalmente em uma área da cidade conhecida naquela época como "triângulo", "formada pelas ruas XV de Novembro, Direita e São Bento" (CINTRÃO, 2011, p. 20). Sedes de clubes, confeitarias, restaurantes, livrarias, redações de jornais e revistas, salas de cinemas, saguões de hotéis e alguns edifícios públicos apresentavam exposições abertas ao público, composto principalmente pela elite paulistana. Lojas de departamentos, como o Mappin Stores, também abriram espaço para artistas realizarem exposições e eventos culturais, nos moldes das lojas de departamentos francesas e americanas (CINTRÃO, 2011).

No início do século $X X$, residências da elite paulistana construídas a partir de modelos de palacetes ${ }^{3}$, com arquitetura no estilo de sobrado, jardins e muitos cômodos, praticavam o colecionismo e abriam seus pavilhões com obras de arte à visitação. "Foi nesse período que os proprietários dos palacetes passaram a abrir as portas para a comunidade artística, oferecendo saraus, reunindo artistas intelectuais e dando início ao mecenato privado que marcou a vida cultural de São Paulo" (CINTRÃO, 2011, p. 41).

Cabe ressaltar que, segundo Cintrão (2011), essas mostras eram realizadas em espaços "alternativos", tendo existido mais de duzentos deles, boa parte deles localizados no "triângulo", no centro de São Paulo. A vida cultural e o mercado das artes eram bastante movimentados no início do século, criando um forte circuito que ultrapassava os poucos espaços institucionalizados. Outros espaços institucionalizados como museus de arte surgiriam no final da década de 1940 com o início das atividades do Masp em 1947 e do MAM em 1948, cujo acervo culminaria na fundação do MAC-USP em 1963.

\section{Método de pesquisa através da memória gráfica}

O estudo aborda o viés da cultura material - segundo autores como Bucaille e Pesez (1989), Meneses (2003), Rede (1996) e Margolin (2009); este último entende o design como um produto social, ligado intrinsecamente ao seu contexto de trabalho, produção e imersão na sociedade -, aplicado à artefatos de memória gráfica.

As pesquisas sobre "memória gráfica" constituem narrativas ligadas à história do campo gráfico, surgindo paralelamente a campos de estudos já estabelecidos, como a cultura visual, a cultura impressa e a cultura material. Segundo Farias (2014), os estudos de memória gráfica partilham de elementos do campo da cultura visual, sobretudo acerca da coleta de dados visuais e organização dos mesmos em bancos de dados, além de compartilhar o "interesse em compreender o modo como a sociedade escolhe ou cria imagens e formas visuais, e, ao mesmo tempo, é em certo sentido refletida em tais imagens e formas" (FARIAS, 2014, p. 203).

Entende-se que a memória gráfica de um equipamento cultural pode, a princípio, ser preservada ao longo de suas publicações impressas. Em museus voltados às artes, é comum que a memória gráfica seja formada por catálogos de obras do acervo, catálogo de exposições, e ainda por impressos como cartazes, convites e folhetos com a programação. Além de peças físicas originais preservadas, a memória gráfica pode ser observada através de registros fotográficos do

\footnotetext{
${ }^{3}$ Residências como a de Paes de Barros, a Vila Maria - uma chácara de Dona Veridiana Valéria da Silva Prado -, Vila Kyrial de Freitas Valle e a residência de Dona Olívia Guedes Penteado com seu Pavilhão Modernista (CINTRÃO, 2011).
} 
local, considerando-se a comunicação externa, fachada, a identificação dos funcionários e a sinalização interna, bem como os materiais característicos do ponto de comercialização do museu, compostos de produtos e objetos tridimensionais que carregam a assinatura gráfica da instituição, tais como os souvenirs.

Em função da necessidade de se referir tanto a exemplos de assinaturas pertencentes às artes gráficas e às composições por processos analógicos, quanto aos projetos atuais realizados por designers e compostos a partir de softwares, desde que pertencentes ao meio impresso, foi proposta a terminologia "assinatura gráfica" para utilização no decorrer das análises, evitando incoerências terminológicas tão corriqueiras no campo do design.

O contexto metodológico empreendido partiu de procedimentos de coleta - a partir de fontes de dados primários junto ao museu Pinacoteca -, seleção, organização, fichamento e análise já aplicados por outros pesquisadores em estudos de memória gráfica (LIMA E MICHELON, 2010; WILLE et al. 2010; ARAGÃO 2010, 2011; ARAGÃO et al. 2012; LIMA et al. 2012; FONSECA, GOMES E CAMPOS, 2016). Cruzados e complementados com levantamentos de dados coletados através de pesquisas de referências impressas e virtuais - livros, pesquisas e artigos -, coletas de história oral (ALBERTI, 2005) - através de entrevistas aos designers Rogério Lira e Carlos Perrone sobre os respectivos projetos para a Pinacoteca - e, quando estes métodos mostravam-se insuficientes pela escassez de registros, no caso de fatos relativamente recentes, contatou-se diretamente os setores das instituições relacionados à pesquisa que pudessem complementar as lacunas - Cedoc Pinacoteca, Setores de Design do MAM e do Masp.

A estruturação da análise gráfica parte de um modo geral da proposta de Michael Twyman (1979), que distingue três grandes grupos de elementos dentro da linguagem gráfica: o grupo dos elementos pictóricos, dos elementos verbais e dos esquemáticos. A análise da memória gráfica considerou as características visuais de cada peça gráfica em si, em paralelo os contextos do campo gráfico e da própria instituição na constituição de uma narrativa que buscou mapear a construção da identidade visual destes museus.

\section{Resultados}

Neste tópico serão mostrados e comentados, em síntese, os principais levantamentos de memória gráfica, com foco na identidade visual, obtidos na pesquisa com os museus paulistanos Pinacoteca do Estado de São Paulo, Masp, MAM-SP e MAC-USP, nesta sequência que segue a ordem cronológica de fundação destes museus. Os resultados trazem mudanças visuais e gráficas que ocorreram na identidade desses museus e destacam os profissionais gráficos envolvidos.

\subsection{Pinacoteca do Estado de São Paulo}

Instituída oficialmente em 15 de novembro de 1905 (AMARAL, 1982), a Galeria de Pintura do Estado - Pinacoteca - foi instalada em uma das salas do edifício do então Liceu de Artes e Ofícios, edifício que passaria aos poucos a ocupar por inteiro. Após ser regulamentada pela Lei № 1271 de 21 de novembro de 1911 enquanto museu estatal - instituição subordinada à Secretaria do Interior e da Justiça -, a Pinacoteca abriu oficialmente suas portas ao público em 24 de dezembro do mesmo ano, com a " $1{ }^{a}$ Exposição Brasileira de Belas Artes" (CAMARGOS; MORAES, 2005, p. 19). 
Em 1912, após a $2^{a}$ mostra de mesmo nome, foi lançado o primeiro catálogo de quadros. Outros catálogos foram publicados nos anos 1914, 1917, 1921, 1926 e $1938^{4}$.

Em suas três primeiras décadas de existência, a composição do acervo da instituição se ligava aos critérios artísticos da burguesia paulistana. As obras provinham, em sua maioria, de doações estritamente acadêmicas, recebidas sem quaisquer critérios de seleção, oriundas das famílias abastadas e dos bolsistas do Pensionado Artístico do Estado de São Paulo. Constituíam, portanto, uma série "ainda distanciada das novas manifestações artísticas" (CAMARGOS, 2007, p. 55) da capital, fato que configurava um cenário de baixa visitação do público, embora a Pinacoteca ainda fosse o único museu de artes do estado.

Na década de 1930 a instituição enfrenta uma fase bastante conturbada, quando ocorre a dispersão de seu acervo, permanecendo fechada para visitação em algumas temporadas e reabrindo ao público em outro endereço. Ainda assim a Pinacoteca resistiu em suas atividades e continuou a ampliar seu acervo através do recebimento de doações.

As características visuais da composição do catálogo de 1912 estão fortemente ligadas às tendências gráficas de seu tempo devido ao uso das molduras curvilíneas em estilo Art Nouveau e presença de elementos decorativos. Entre os catálogos de 1912 e 1926, mostrados na figura 1, fica evidente uma tendência de geometrização das formas, neste último com elementos decorativos em sua maioria quadriculados, preenchidos de preto, adornando a moldura fina de uma única linha. As cantoneiras e os elementos centrais derivam dessa mesma linha estética neste catálogo assinado pela Cia. Paulista de Papéis e Artes Graphicas.

Os documentos impressos, ou ofícios, preservados no acervo do Cedoc constituem uma amostra ampla e temporalmente extensa, onde se observa ainda mais variações da assinatura gráfica da instituição que nos catálogos de obras. Os primeiros documentos impressos, datados de 1912 e 1914 respectivamente, configuram raras ocorrências de fontes de memória gráfica que preservam a assinatura gráfica da Pinacoteca desse período. No ofício de 1914, mostrado na figura 1, a assinatura gráfica foi caracterizada pelo uso de uma tipografia display, com letras que apresentam variação de espessura, uma leve curvatura nas hastes e traços diagonais com terminações suavemente arredondadas - características decorativas indicam que esta é uma tipografia com traços Art Nouveau, tendência em voga no campo das artes gráficas daquele momento. Na década de 1930, os ofícios são caracterizados visualmente por uma assinatura gráfica composta em arranjo curvilíneo, semicircular, formado pelo nome do museu e discretos traços divisores lineares, que podem ser observados na figura 1.

\footnotetext{
4 Os agentes do campo gráfico envolvidos com a memória gráfica da Pinacoteca foram mapeados, destacando-se a Tipografia Siqueira Nagel, a Tipografia Augusto Siqueira, a Casa Vanorden, a Cia. Paulista de Papéis e Artes Gráficas e a Imprensa Oficial do Estado de São Paulo neste período das três primeiras décadas, posteriormente assinaram catálogos a Gráfica Paulista de João Bentivegna, as Escolas Profissionais Salesianas, a Gráfica Canton e novamente a Imprensa Oficial do Estado de São Paulo.
} 


\section{Artigo Completo}
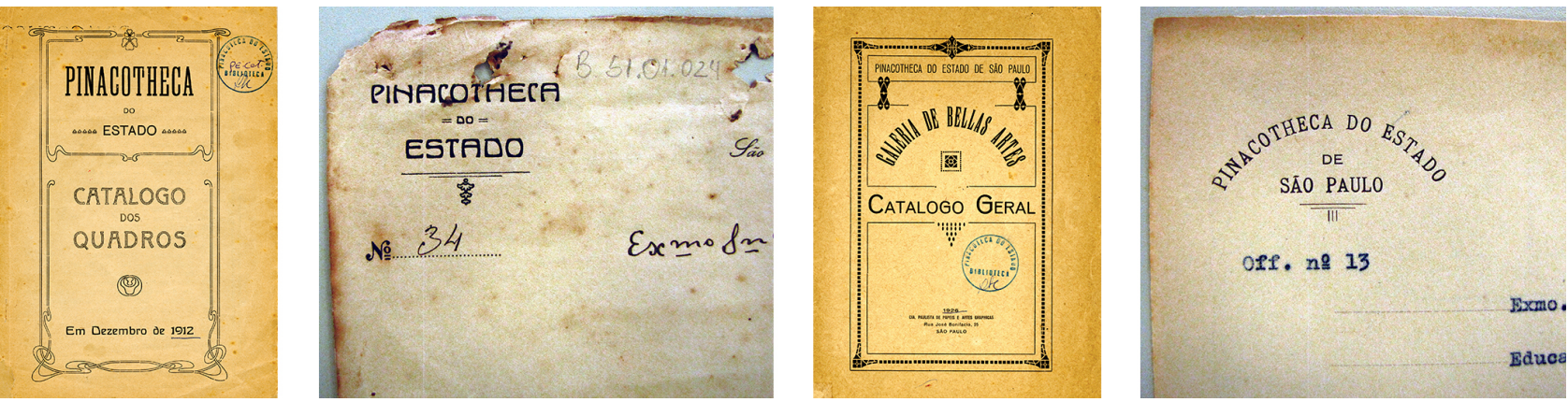

Figura 1 Capa do catálogo - Pinacotheca do Estado, Catalogo dos Quadros, Em Dezembro de 1912 - [s.I.;s.n.]. Detalhe da assinatura gráfica da Pinacoteca no documento timbrado, 1914. Capa do catálogo- Pinacotheca do Estado de São Paulo, Galeria de Bellas Artes, Catalogo Geral - 1926, Cia. Paulista de Papéis e Artes Graphicas, São Paulo. Documento timbrado, detalhe, 1933 - Pinacotheca do Estado de São Paulo. Originais escaneados. Fonte: Acervo Cedoc /

Pinacoteca de São Paulo.

O período que vai da década de 1940 até o final da década de 1980, compreende uma fase em que a instituição passa a ser, sucessivamente, subordinada a diferentes órgãos públicos e secretarias de governo, ao passo que se consolida como museu e, pouco a pouco, conquista sua sede definitiva. Neste período a influência política na identidade da Pinacoteca é flagrante na presença do brasão das Armas Nacionais e do brasão das Armas do Estado de São Paulo junto à assinatura gráfica em ofícios e alguns catálogos, conforme mostrado na figura 2.
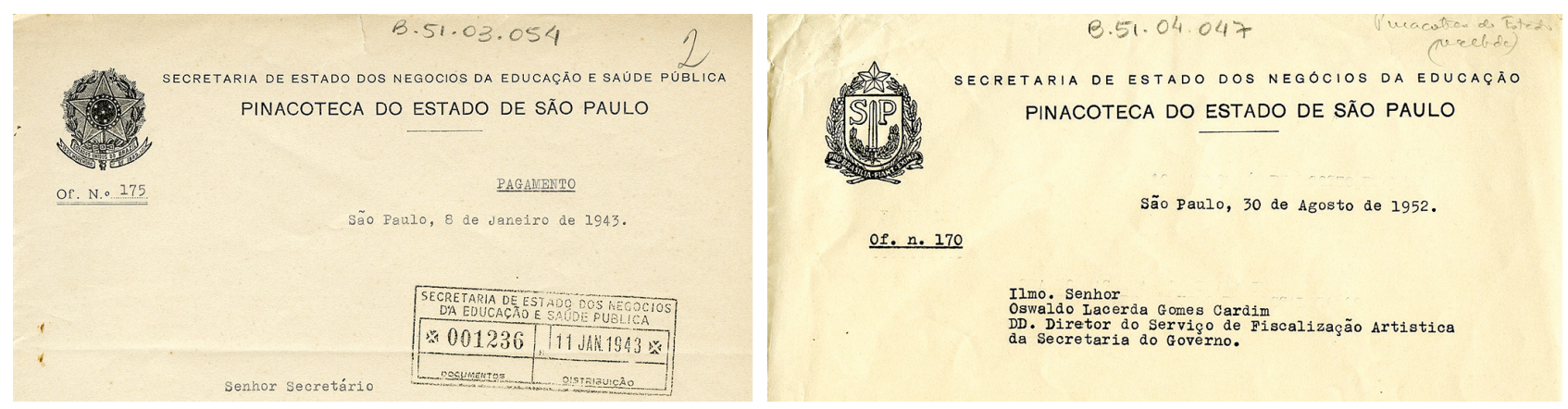

Figura 2 Documento timbrado, 1943 - Secretaria de Estado dos Negócios da Educação e Saúde Pública, Pinacoteca do Estado de São Paulo. Documento timbrado, 1952 - Secretaria de Estado dos Negócios da Educação. Originais escaneados. Fonte: Acervo Cedoc / Pinacoteca de São Paulo.

Questões de tombamento do edifício e a conquista da totalidade do espaço, bem como a extensa reforma arquitetônica comandada pelo arquiteto Paulo Mendes da Rocha - que reestruturou e modernizou o edifício para abrigar o museu -, refletiram na identidade da Pinacoteca a partir dos anos 1990. No início desta década uma composição com uma referência visual ao edifício da Pinacoteca junto ao nome da instituição passou a assinar materiais de exposições como convites, cartazes, catálogos, figurando também em documentos oficiais e papéis de fax. No projeto original, assinado pelo designer Rogério Lira - contratado pela diretora Maria Alice Milliet, que assumiu o cargo em 1989 -, a referência imagética da fachada do edifício 
foi estilizada, configurando o primeiro elemento visual presente na assinatura do museu, o que pode ser observado na figura 3.

Ainda na primeira metade da década de 1990 a Pinacoteca passou por uma importante reforma arquitetônica. Projetada por Paulo Mendes da Rocha e Eduardo Colonelli, durante a gestão do diretor Emanoel Araujo, iniciada em 1992, a reforma modificou a entrada do edifício, reestruturou o fluxo de circulação e área de luz do museu e recebeu o Prêmio de Arquitetura Contemporânea Mies Van der Rohe para a América Latina (CAMARGOS, 2007). Após a reforma a Pinacoteca bateu recordes de visitação, colocando o museu em destaque no cenário nacional. $O$ designer Carlos Perrone foi convidado por Araújo para desenvolver os projetos de identidade visual e de sinalização para a Pinacoteca. Perrone retirou o caráter fotográfico (imagético) do ícone anterior, conforme mostrado na figura 3, propondo um desenho mais construtivo e geometrizado, dentro do mesmo recurso de referência à fachada e utilizou a fonte Futura projetada em 1927 por Paul Renner - em vermelho para grafar o nome do museu.

A assinatura gráfica criada por Perrone ficou em uso por aproximadamente 13 anos. Em 2011, no final da gestão de Marcelo Mattos Araújo, foi substituída por uma identidade visual projetada pela agência F/Nazca que se apresentava mais colorida e menos rígida, mas teve uma vida curta (figura 3). Na profusão de cores aleatórias que atingia a própria assinatura gráfica do museu, a relação visual com a arquitetura se tornou frágil e o nome do museu menos legível, além dos diversos problemas técnicos em sua construção que contribuíam com a má legibilidade e a baixa pregnância. Trata-se de uma fase em que a Pinacoteca parece se identificar e se comunicar de modo efêmero na assinatura gráfica e nos materiais observados.

Em um novo projeto, a identidade visual atual [2018], lançada em 2016 na gestão de Tadeu Chiarelli com projeto da mesma agência, desmembra a referência arquitetônica em elementos gráficos com múltiplas possibilidades de aplicação em um projeto complexo de identidade e insere um novo nome para o museu: "Pina_" (figura 3) - novidades que carecem de um distanciamento temporal para análise dos efeitos que provocarão na memória gráfica da Pinacoteca.
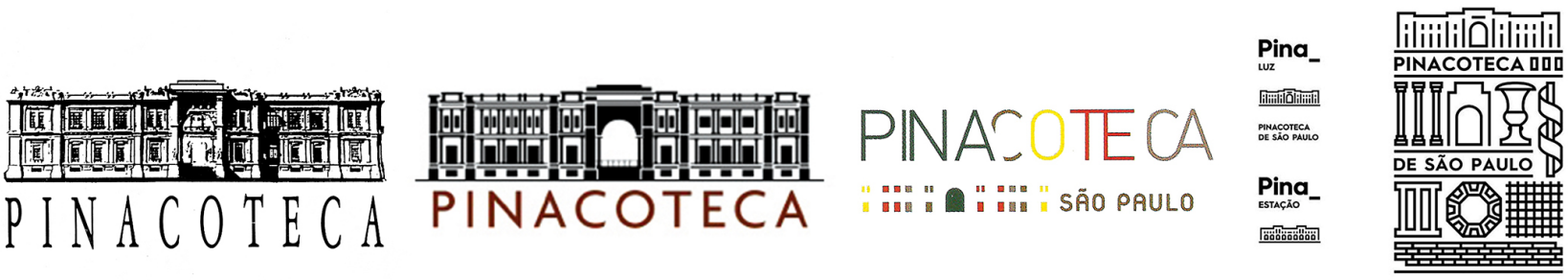

Figura 3 Detalhe da assinatura gráfica da Pinacoteca no cartaz de divulgação da exposição temporária "Benedito Calixto - Memória Paulista", 1990. Autoria de Rogério Lira. Original escaneado. Fonte: Acervo Cedoc / Pinacoteca de São Paulo. Assinatura gráfica projetada por Carlos Perrone em 1998 para a Pinacoteca. Fonte: acervo pessoal de Carlos Eduardo Perrone, Desenho Lógico (imagem enviada por e-mail). Assinatura gráfica da Pinacoteca, 2011. Fonte: Maringelli e Bevilacqua (2013, p. 160). Imagem de lançamento da nova identidade visual da Pinacoteca, divulgada em 25 de janeiro de 2016. Fonte: Pinacoteca [s. d. c.].

A partir das análises em sequência cronológica, considerando as mudanças mais impactantes na instituição da década de 1990 em diante, fica visível que as mudanças de 
identidade da Pinacoteca estão, de certa forma, pautadas pelas mudanças de gestão da instituição. A dinâmica se assemelha, portanto, à de uma identidade atrelada a um órgão público como marcas de cidades, estados e países, que frequentemente são alteradas a cada nova gestão política, salvo algumas exceções. Acredita-se que tais mudanças possam estar mais relacionadas às visões pessoais dos gestores do que guiadas por princípios institucionais ou políticas internas estabelecidas pelo museu, refletindo a instituição de modo efêmero em sua identidade visual.

\subsection{Museu de Arte de São Paulo}

O Masp teve o início de suas atividades em 2 de outubro de 1947 na sede dos Diários Associados sede das empresas de comunicação de seu fundador, Assis Chateaubriand ${ }^{5}$-, à rua 7 de Abril, 230, no centro de São Paulo. O espaço inicial de um pavimento com cerca de mil metros quadrados foi projetado pela arquiteta Lina Bo Bardi ${ }^{6}$, esposa do diretor técnico do museu, Pietro Maria Bardi ${ }^{7}$. "A situação na cidade indicava a necessidade de difundir conhecimentos específicos que justificavam a abertura de um museu diferenciado da já existente Pinacoteca do Estado, continuadora de uma museologia oitocentesca" (BARDI, 1992, p. 15).

A nova sede do museu, na Avenida Paulista, no 1578, foi inaugurada anos mais tarde, em 7 de novembro de 1968, quando a nomenclatura do museu passou a homenagear seu fundador Museu de Arte de São Paulo Assis Chateaubriand -, recém falecido (SIMÕES, 2008). Na nova sede o museu inovou ao expor as obras em amplas salas com os painéis de cristal temperado sobre uma base de concreto aparente, projetados por Lina (BARDI, 1992). Uma reforma estrutural externa foi necessária em meados dos anos 1990 e culminou na pintura das vigas em vermelho, auxiliando na impermeabilização do concreto (BARDI, 1992), o que marcou a imagem da arquitetura do Masp na Avenida Paulista definitivamente.

Inicialmente o museu se comunicava com o público através da denominação "Museu de Arte", conforme imagem da entrada na Rua 7 de Abril (figura 4); posteriormente, na avenida Paulista, utilizava por extenso sua nomenclatura completa (figura 4). A sigla Masp aparece mais tardiamente na década de 1990 na revista do museu (figura 4). A assinatura gráfica do Masp foi encomendada por Fábio Magalhães, no período em que foi curador chefe do museu (1989-1994), ao publicitário catalão Francesc Petit ${ }^{8}$, que propôs um desenho da Paulista e o uso em conjunto com a sigla Masp em vermelho, que pode ser observada na figura 4. Houve um manual de identidade visual do Masp, produzido pelo designer lago da Silva Francisco quando estagiou na instituição entre 2013 e 2014 (FRANCISCO, s. d.), com intenção de criar uma normatização para o uso da assinatura gráfica.

\footnotetext{
${ }^{5}$ Francisco de Assis Chateaubriand Bandeira de Melo, 1892, Umbuzeiro (PB) - 1968, São Paulo.

${ }^{6}$ Achillina Bo, conhecida como Lina Bo Bardi, 1914, Roma (Itália) - 1992, São Paulo.

7 Pietro Maria Bardi, 1900, La Spezia (Itália) - 1999, São Paulo.

${ }^{8}$ Francesc Petit Reig, 1934, Barcelona (Espanha), - 2013, São Paulo.
} 

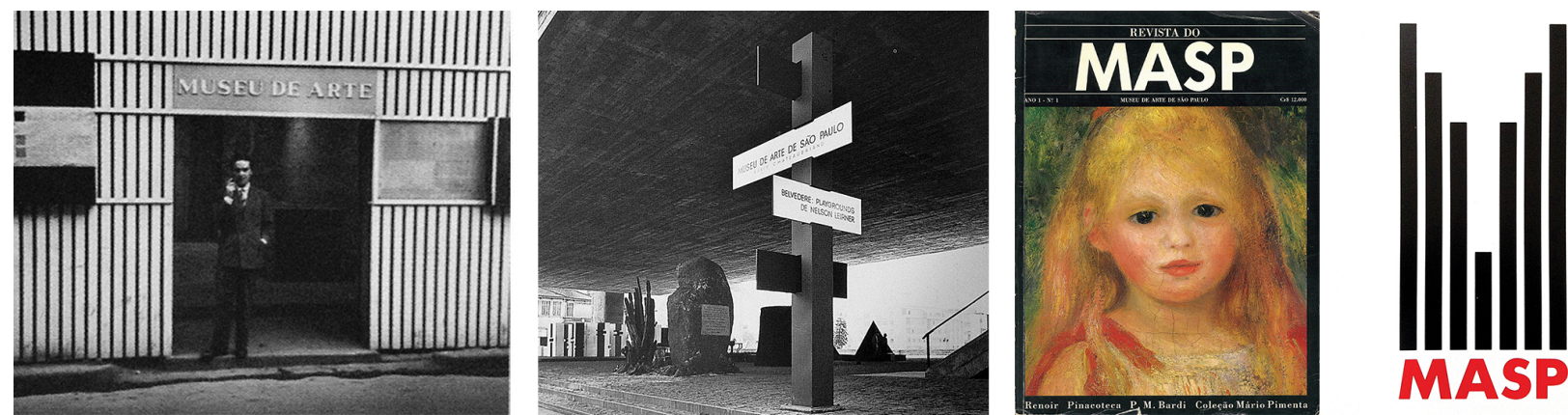

Figura 4 Entrada do Masp em sua primeira sede na Rua 7 de Abril [1940-1950]. Fonte: Simões (2008). Totem indicativo no vão livre do Masp na Av. Paulista. Sem data. Sem indicação do fotógrafo. Fonte: Bardi (1997). Capa da primeira edição da Revista Masp, ano 1, no 1, 1992. Original escaneado. Fonte: acervo pessoal. Assinatura gráfica do Masp desenhada por Francesc Petit. Original publicado na Revista Masp, ano 1, no 1, 1992. Fonte: Petit (1992).

Através de referências iconográficas e dos dados bibliográficos levantados em livros e catálogos sobre o Masp (BARDI 1992; BARDI 1997; SIMÕES, 2008) foi possível observar que o museu se identificava, desde sua fundação em 1947 até o final da década de 1980, com o nome por extenso através de tipografias que não apresentavam recorrência constante entre as publicações. Uma identificação com recorrências relativamente padronizadas pôde ser observada a partir dos anos 1990, com o desenho de Petit que representa a Avenida Paulista, as cores vermelho e preto e a sigla Masp, bem como o nome por extenso, grafados frequentemente na fonte Futura. Nas últimas décadas, essa forma constante de identificação foi continuada recentemente através do uso apenas do logotipo ${ }^{9}$, sem o desenho dos prédios da Paulista, a partir do manual de aplicação da marca Masp criado em 2016 pelo setor de Design do Masp ${ }^{10}$, o que colaborou para a imagem institucional do museu enquanto marca, e criou pregnância através do fácil reconhecimento visual e da gestão de marca usada em suas produções bibliográficas, produtos e materiais de comunicação em meios impressos e digitais.

\subsection{Museu de Arte Moderna de São Paulo}

Em 1948 o MAM-SP foi fundado como uma associação civil sem fins lucrativos, encabeçada por Francisco Matarazzo Sobrinho ${ }^{11}$ e Yolanda Penteado ${ }^{12}$, junto com um grande grupo de artistas, concomitante ao surgimento do MAM no Rio de Janeiro (MAM-RJ), ambos inspirados pelo Museum of Modern Art (MoMA) de Nova lorque, fundado em 1929, e frutos do ambiente de grande efervescência cultural e progresso socioeconômico que caracterizou o Brasil na década de 1940 (ZANINI, 1983). A sede inicial, localizada à Rua Sete de Abril, 230 no edifício dos Diários Associados - assim como o Masp, que já funcionava nesse endereço -, ocupava o terceiro andar com projeto interno do arquiteto Villanova Artigas (HORTA, 1995). Com a transferência do acervo do MAM-SP em 1958 para o Ibirapuera e a criação da Fundação Bienal de São Paulo em 1962 tornando as Bienais independentes do museu - o MAM-SP foi praticamente extinto pouco depois,

\footnotetext{
${ }^{9}$ Bastante similar quanto à fonte tipográfica e ao código cromático já empregados anteriormente.

10 O Setor de Design do Masp foi implantado por Raul Loureiro após uma reestruturação dos setores do museu em 2014 e desenvolve todos os materiais gráficos e interfaces visuais do museu.

${ }^{11}$ Francisco Antônio Paulo Matarazzo Sobrinho, conhecido como Ciccillo Matarazzo, 1898 - 1977, São Paulo.

${ }^{12}$ Yolanda de Ataliba Nogueira Penteado, 1903, Leme (SP) - 1983, Stanford (Estados Unidos).
} 
em 1963, com a doação de todo o seu acervo à USP assinada por Francisco Matarazzo Sobrinho. Do MAM-SP só restou o nome, que continuaria em uso pelo grupo de artistas, sócios e amigos que assumiram o museu. A doação foi a base para a fundação do MAC-USP.

No mesmo ano em que ficaram sem o acervo (1963), os sócios planejaram reerguer o museu. $\mathrm{O}$ grupo promoveu algumas exposições em locais diversos e a sede do museu passou por alguns outros endereços na capital até o retorno ao Ibirapuera, desta vez ocupando o Pavilhão Bahia, abandonado como antigo depósito da Bienal (HORTA, 1995). "A direção do museu encomendou ao arquiteto Giancarlo Palanti o projeto de instalação interna no pavilhão, a programação visual do museu e o logotipo. A mostra Panorama da Arte Atual Brasileira, em 1969, marcou a reinauguração do museu em sua nova sede" (GAMA, 1998).

O logotipo do MAM-SP foi composto por Palanti com a sigla em letras minúsculas, "o ' $a$ ' colorido ora em vermelho ora em azul, no meio dos dois ' $m$ ' cinza" (HORTA, 1995, p. 36). A fonte Helvetica em peso bold foi utilizada com letras minúsculas na composição da sigla, formada pelas iniciais do nome Museu de Arte Moderna, sinalizando novos tempos na instituição (figura 5).

\section{Universidade da Bahia e onde Juscelino comera acarajé com Cicillo e Yolanda -, em sede do MAM foi feita segundo projeto do arquiteto Giancarlo Palanti. Palanti cuidou também da programação visual do museu, redesenhando o logotipo do mam com as três letras minúsculas, o "a" colorido ora em vermelho ora em azul, no meio dos dois "m" cinza.}

Figura 5 Logotipo do MAM-SP, sigla, desenhado por Giancarlo Palanti em 1968, inserida em meio ao texto. Original escaneado. Fonte: Horta (1995, p. 36).

Através de alguns catálogos da mostra "Panorama de Arte Atual Brasileira" observou-se que, além das aplicações do logotipo "mam" em versões que mesclavam cinza com os matizes vermelho ou com azul - aplicados na letra " $A$ " - conforme a proposta de Palanti, houve outros usos da sigla sobre fundo preto, azul, cinza e bege, com a letra " $A$ " apenas em contorno, com configurações estéticas variadas, conforme a primeira imagem da figura 6. Uma padronização nos catálogos da mostra acontece a partir de 1983 (figura 6), com projeto gráfico de Emilie Chamie, seguido anualmente até o catálogo da exposição realizada em 1991 (CINTRÃO, 1997).

Chamie padroniza a aplicação do logotipo do MAM-SP nas cores preto e vermelho, mais próximas ao cinza e vermelho propostos originalmente por Palanti. Aparentemente em uma tentativa de maior distinção do MAM existente no Rio de Janeiro, a designer opta por uma associação com as cores da bandeira do Estado de São Paulo.

A identidade visual do museu a partir do uso da sigla como logotipo, criado logo no início desta segunda fase de existência, em 1968, o representa até hoje. A partir do arquivo digital que apresenta o programa de identidade visual do Museu de Arte Moderna de São Paulo - criado entre outubro de 2002 e março de 2003 pelas designers Christine Miocque e Claudia Warrak (2003), do estúdio Miocque Warrak Design - foi possível observar que houve diversas adequações às necessidades de identificação e comunicação do museu. $O$ programa define como assinatura institucional um conjunto que inclui a sigla e o nome por extenso do museu, que claramente o 
distingue de seu homônimo carioca (figura 6).

O guia de identidade visual do MAM-SP - publicado em 2013 em formato digital, foi assinado pelo estúdio Sinlogo, com direção de arte de Alois di Leo e Filipe Grimaldi - compreende uma atualização da identidade do museu na nova gestão de Milú Vilella, com curadoria de Felipe Chaimovich (MAM, 2013). Segundo a equipe da Sinlogo (s. d.), a instituição solicitou que toda a identidade visual do museu, afetada com o crescimento das novas mídias sociais, fosse remodelada. Ao comparar o logotipo redesenhado em 2013 com seu antecessor foi possível observar que houve um ajuste no espaço entreletras e no peso da fonte para bold, se aproximando mais da versão de 1983 desenhada por Emilie Chamie (figura 6). Nesse guia (MAM, 2013) o logotipo do museu, em sua versão principal, faz uso de preenchimento gradiente com duas tonalidades de vermelho na letra "a". A versão do logotipo com o nome da instituição por extenso blocado abaixo da sigla com um pequeno espaço entre eles, compromete aplicações reduzidas e o arejamento do conjunto.

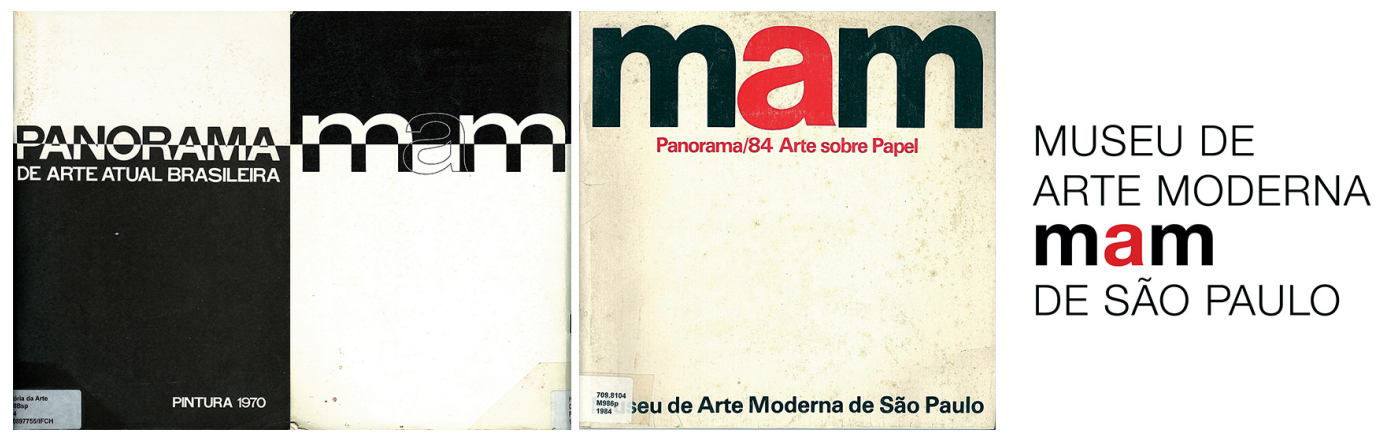

\section{mam}

Figura 6 Catálogos da mostra "Panorama de Arte Atual Brasileira" - primeira e quarta capa, 1970 e primeira capa, 1984. Originais escaneados. Fonte: MAM (1970; 1984). Assinatura institucional do MAM-SP apresentada no programa de identidade visual projetado por Miocque Warrak Design em 2003. Fonte: Miocque e Warrak (2003). Logotipo do MAM-SP pelo estúdio Sinlogo, 2013. Fonte: MAM (2013).

De fato, a identidade do museu tomou uma forma dinâmica com uma maior integração entre os meios impresso e digital, considerando os exemplos de impressos no manual e o site atual do museu (MAM, s. d.), bem como o envio de e-mails com a programação. Uma consequência disso foi que algumas regras de legibilidade que seguiam os preceitos do design concretista, prezados pelo guia de identidade utilizado anteriormente, tiveram de ser descontinuadas. As extensas áreas de fundo preto ou vermelho dão espaço para a predominância no uso do branco como plano de fundo da identidade. Atualmente os materiais de identidade, comunicação impressos e digitais do museu são desenvolvidos no setor de design do museu implantado em 2014, sob a coordenação de Camila Dylis Silickas (2016).

O MAM-SP que, ao longo de sua trajetória de altos e baixos, se identificava institucionalmente pelo nome grafado por extenso nas publicações das décadas de 1940 e 1950, após ser despojado de seu patrimônio e retomado por um grupo que o levou adiante, passou a ter uma sigla configurada como um logotipo, uma assinatura gráfica, utilizada em todos os pontos de contato do museu. Esta estrutura de assinatura gráfica, embora tenha sido renovada esteticamente com o passar dos anos - em suas configurações físicas de preenchimento 
cromático, espacejamento e espessura dos caracteres -, foi mantida em sua essência até a atualidade. Ainda que o nome do MAM-SP esteja atrelado a um movimento artístico, temporal, o museu, através de sua atuação, posicionamento e identidade institucional, vem se renovando com o passar do tempo e possui uma marca de peso entre os museus de arte. É o caso mais expressivo de branding aplicado a instituições desse tipo observadas, que, em conjunto com ações de design e marketing, sem dúvida reflete na força da identidade deste museu.

\subsection{Museu de Arte Contemporânea}

A fundação do MAC-USP acontece a partir da doação de todo o acervo MAM-SP à Universidade de São Paulo, ocorrida em meio a uma crise do museu em 1963. O MAC se destacou pela circulação de seu acervo em mostras nas décadas de 1960-70, época em que proliferavam as galerias de arte (ZANINI, 1983). Funcionando a partir de 1963 no terceiro andar do pavilhão da Bienal no Ibirapuera, a gestão inicial de Walter Zanini, que duraria quinze anos, organizou o acervo e promoveu exposições contemporâneas (O MUSEU, 1990), com posterior transferência para um edifício na USP. O logotipo da instituição seria criado ainda sob essa gestão, em 1970, pelo designer Alexandre Wollner (figura 7).

Wollner caracteriza a sigla, com as iniciais do nome do museu, a partir de letras maiúsculas de traço fino, livre de serifa ou qualquer ornamento, cuja referência vem do movimento concreto que o inspira. No logotipo as letras " $M$ " e " $A$ " apresentam um desenho contínuo, como se feitas com uma única linha, mantendo as linhas inclinadas em diagonal apoiadas nas linhas verticais. $A$ letra " $C$ " e a haste da letra " $A$ " representam outras duas linhas que compõem o logotipo, criado com o mínimo de elementos necessários. O logotipo permanece em uso até a atualidade.
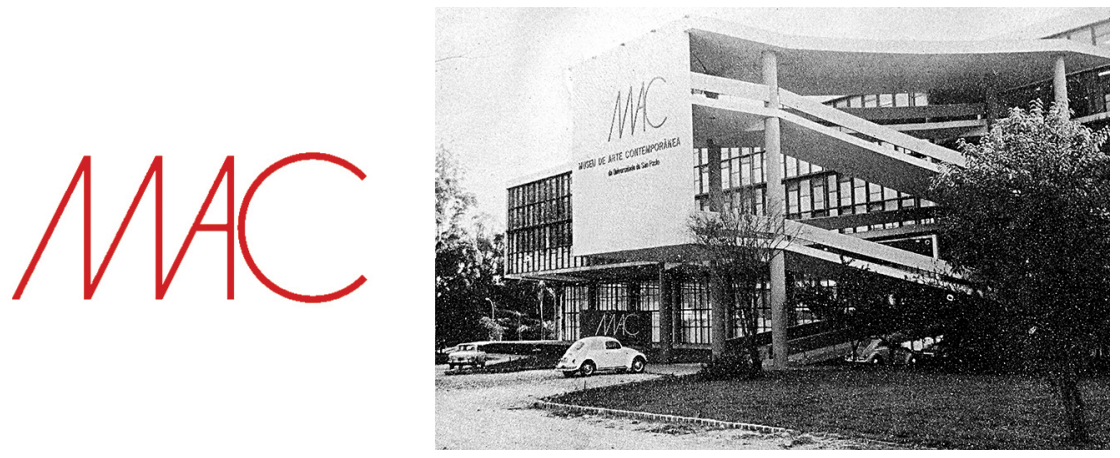

Figura 7 Logotipo criado para o Museu de Arte Contemporânea em 1970 pelo designer Alexandre Wollner. Fonte: Wollner (2003). O logotipo do MAC sinaliza a entrada e a rampa de acesso ao museu no pavilhão da Bienal no Ibirapuera. Fotografia: Gerson Zanini, German Lorca e Athayde de Barros. Fonte: MAC (1973, p. 2).

Hoje o MAC-USP está localizado na Av. Pedro Álvares Cabral, em frente ao Parque do Ibirapuera, em um edifício projetado nos anos 1950 pelo arquiteto Oscar Niemeyer, possuindo um acervo de cerca de 10 mil obras de arte. 


\section{Considerações sobre o cenário dos museus de arte paulistanos na questão da identidade visual}

Partindo de uma gama mais ampla envolvendo definições e o surgimento de museus de arte, para afunilar em questões mais específicas, traçou-se o contexto em que se deu o desenvolvimento do cenário artístico em São Paulo, fundamental para se compreender o momento do surgimento dos principais museus da cidade.

Um estudo de memória gráfica envolve, consequentemente, além das relações materiais, uma observação da sociedade na qual estão inseridas, das instituições similares e do campo gráfico. As histórias da Pinacoteca, Masp, MAM-SP e MAC-USP, aqui brevemente recuperadas para compor o contexto artístico museológico paulistano do século passado, trouxe dados acerca do surgimento, atuação e, principalmente, ressaltou a identidade visual dessas instituições.

Uma mudança de paradigma na identidade visual da Pinacoteca ocorre na década de 1990, e vem definitivamente alterar o cenário de como este museu se apresenta graficamente. Após o tombamento do edifício e a conquista da exclusividade de uso de seu espaço, o projeto gráfico de Rogério Lira, em 1990, fez a conexão do nome da Pinacoteca com a referência arquitetônica imagética de seu edifício. Na mesma década, o museu passa por uma importante reforma arquitetônica, que moderniza o edifício e abre espaço para receber grandes exposições internacionais, ampliando significativamente sua atuação - cujos reflexos se dariam em todas as instâncias, incluindo sua identidade visual em materiais gráficos e de sinalização, com o projeto do designer Carlos Perrone. Essa assinatura gráfica da Pinacoteca teria a mais longa duração, mantendo-se em uso por cerca de 13 anos. Em um panorama mais recente, observou-se que esta relação entre a identidade visual do museu e sua arquitetura vem sendo atualizada e permanece em voga. Cabe lembrar que em 2005 a Pinacoteca deixou de ser gerida como uma repartição pública e passou a ser administrada integralmente pela sociedade civil através da Associação Amigos da Pinacoteca, fundada em 1992.

O panorama mencionado, ao atentar também para a atuação do Masp e do MAM-SP, trouxe, acima de tudo, referências visuais e particularidades acerca da memória gráfica dessas instituições. O Masp, que assinava seu nome por extenso sem uma recorrência constante em publicações caracterizadas muitas vezes por imagens de obras de arte de seu acervo, passou a ter uma assinatura gráfica própria partir da década de 1990. O projeto de Francesc Petit, que compreendia a sigla Masp junto ao desenho que remete à arquitetura da Avenida Paulista, perdurou até há pouco tempo atrás, usado atualmente sem os elementos visuais, em uma atualização proposta pelo designer Raul Loureiro.

No caso do MAM-SP observa-se nos materiais gráficos uma identidade visual predominantemente institucional, implementada desde o final da década de 1960, através de uma assinatura gráfica proposta por Giancarlo Palanti, após a doação de todo o acervo que quase o extinguiu e a retomada do museu por um grupo de artistas. A assinatura gráfica passou por atualizações no decorrer de seu uso por Emilie Chamie na década e 1980, e pelos estúdios Miocque Warrak Design em 2003 e Sinlogo em 2013, sem perder suas características de origem. A permanência duradoura dessa assinatura na identidade visual do museu até a atualidade mostrouse pioneira entre os museus paulistanos observados. O MAC-USP, que surge a partir da doação de obras vindas do MAM-SP na década de 1960, passa a ter um logotipo de sua sigla criado por Alexandre Wollner na década seguinte, utilizado até hoje. 
É possível traçar um breve paralelo entre as assinaturas gráficas que marcaram época destes quatro museus de arte (figura 8) e relacioná-las ao uso das cores do Estado de São Paulo, preto e vermelho, bem como ao uso de fontes tipográficas modernas, sem serifas, como a Futura identificada nos logotipos da Pinacoteca e do Masp e a Helvetica, utilizada no logotipo do MAM. Graficamente, as assinaturas da Pinacoteca, principalmente a criada por Perrone - em uso pelo maior período até então -, e a do MASP criada por Petit, fizeram uso de referências arquitetônicas importantes para a cidade, auxiliando no reconhecimento destes locais. Já o MAM e MAC se identificam pelo uso das siglas como logotipos e apresentaram maior consistência de uso nas aplicações observadas.
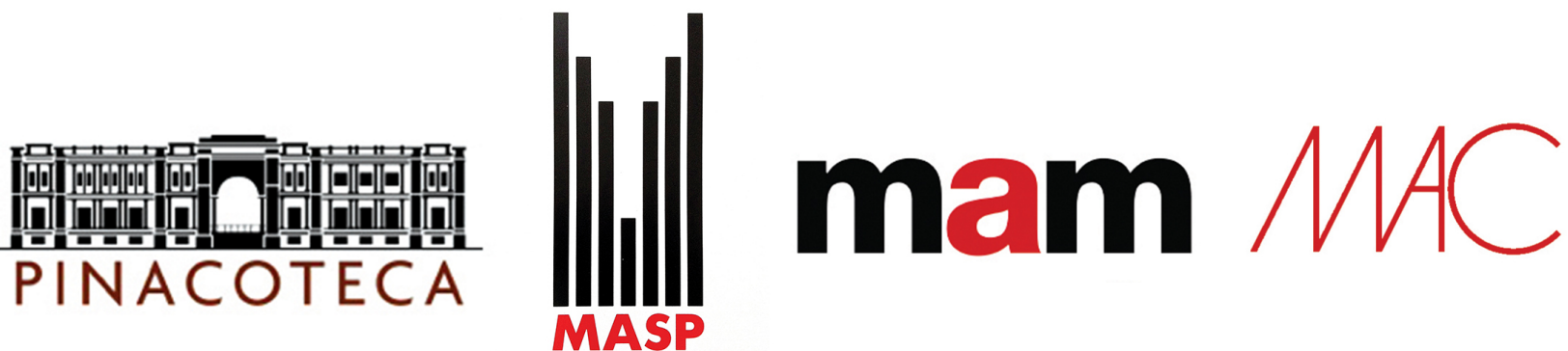

Figura 8 Assinatura gráfica projetada por Carlos Perrone em 1998 para a Pinacoteca. Fonte: acervo pessoal de Carlos Eduardo Perrone, Desenho Lógico (imagem enviada por e-mail). Assinatura gráfica do Masp projetada por Francesc Petit. Original publicado na Revista Masp, ano 1, no 1, 1992. Fonte: Petit (1992). Logotipo do MAM-SP, projetado originalmente por Giancarlo Palanti, versão redesenhada pelo estúdio Sinlogo, 2013. Fonte: MAM (2013). Logotipo do Museu de Arte Contemporânea, projetado em 1970 pelo designer Alexandre Wollner. Fonte: Wollner (2003).

A discussão de identidade institucional dos museus está em alta e envolve, entre muitos outros aspectos, os de posicionamento, branding, ações de marketing e design. Estes e outros fatores, internos e externos aos museus, cooperam para a formação, e percepção por parte do público de espectadores, curadores e mantenedores, de uma identidade institucional.

O levantamento e análise desse acervo gráfico contribuiu para a identificação de períodos, tendências estéticas e personagens da história gráfica paulistana envolvidos com a memória gráfica destes museus ao longo de suas trajetórias, que em alguns casos mostrou-se em constante transformação.

\section{Referências}

ALBERTI, Verena. Manual de historia oral. $3^{\text {a }}$ ed. Rio de Janeiro, RJ: FGV, 2005.

AMARAL, A. Aracy. A Pinacoteca do Estado. In: FUNARTE. MUSEUS - Pinacoteca do Estado de São Paulo. Rio de Janeiro: Ministério da Educação e Cultura, Secretaria da Cultura, Fundação Nacional de Arte, 1982.

ARAGÃO, Isabella Ribeiro. Um breve panorama dos catálogos de tipos das fundidoras Funtimod e Manig. In: Anais do 9o P\&D Design - Congresso Brasileiro de Pesquisa e Desenvolvimento em Design. São Paulo: PPG em Design | Universidade Anhembi Morumbi, AEND-Brasil, 2010. 
O plural e o singular nas composições visuais dos rótulos de bebida. In: CAMPELLO, Silvio Barreto; ARAGÃO, Isabella. Imagens comerciais de Pernambuco: ensaios sobre os efêmeros da Guaianases. Recife: Néctar, 2011.

ARAGÃO, I. R. et al. Desenvolvimento de instrumento para analisar os atributos formais das descrições do produto e os logotipos das Imagens Comerciais de Pernambuco. In: Anais do 10 P\&D Design - Congresso Brasileiro de Pesquisa e Desenvolvimento em Design. São Luís: UFMA, 1860-1869, 2012.

BARDI, Lina Bo. Museu de arte de São Paulo. In: Museu de arte de São Paulo; São Paulo Art Museum. Coautoria de Lina Bo Bardi, Aldo van Eyck. São Paulo, SP: Inst. Lina Bo e P. M. Bardi. Lisboa: Blau, c1997 (não paginado).

BARDI, Pietro Maria. História do Masp. São Paulo, SP: Quadrante, 1992.

BRASIL. Lei no 11.904, de 14 de janeiro de 2009. Institui o Estatuto de Museus e dá outras providências. Publicado originalmente em: Diário Oficial [da República Federativa do Brasil] , Brasília, DF, 15 jan. 2009. Seção I, p. 1. Disponível em: <http://www.planalto.gov.br/ccivil_03/_ato2007-2010/2009/lei/l11904.htm>. Acesso em: 27 mai. 2017.

BUCAILLE, Richard. PESEZ, Jean-Marie; Cultura Material. In: Enciclopédia Einaudi. Lisboa, IN-CM, vol. 16 - Homo - Domesticação - Cultura Material, p. 11-47, 1989.

CAMARGOS, Marcia. A Pinacoteca em Oito Tempos: Um Ensaio Histórico. Pinacoteca in Eight Stages: A Historical Essay. In: Araújo, M. M.; CAMARGOS, M. (Orgs.). Pinacoteca: a história da Pinacoteca do Estado de São Paulo. [Pinacoteca do Estado: a história de um museu ]. São Paulo: Artemeios, 2007, p. 35-136.

CAMARGOS, Marcia; MORAES, Maria Luiza. Pinacoteca do Estado de São Paulo, 1885-2005, Cronologia. In: 100 Anos da Pinacoteca: A formação de um acervo. São Paulo: Pinacoteca do Estado de São Paulo, 2005.

CINTRÃO, Rejane. Algumas exposições exemplares: as salas de exposições na São Paulo de 1905 a 1930. Porto Alegre: Zouk, 2011.

FARIAS, Priscila. On graphic memory as a strategy for design history. In: Proceedings of the $\mathbf{9}^{\text {th }}$ Conference of the International Committee for Design History and Design Studies. São Paulo: Blucher, p. 201-206, 2014. Disponível em <http://www.proceedings.blucher.com.br/articledetails/on-graphic-memory-as-a-strategy-for-design-history-13838>. Acesso em: mar. 2016.

FONSECA, L. P., GOMES, D. D.; CAMPOS, A. P. Conjunto Metodológico para Pesquisa em História do Design a partir de Materiais Impressos. In: Infodesign - Revista Brasileira de Design da Informação / Brazilian Journal of Information Design. São Paulo, v. 13, no 2 [2016], p. 143-161. Disponível em: <https://www.infodesign.org.br/infodesign/article/view/481/285>. Acesso em: nov. 2016.

FRANCISCO, lago da Silva. [Currículo e Portfolio]. Sem data. Disponível em: <https://www.behance.net/IgsFrah>. Acesso em: nov. 2016.

GAMA, Mara. Um prédio polêmico: Museu foi instalado em 1968 sob a marquise do Ibirapuera, idealizada por Oscar Niemeyer; Lina Bo Bardi projetou a reforma do prédio, mas depois se 
arrependeu e pediu a demolição. In: FOLHA de S. Paulo. Especial: Arquitetura. São Paulo, terça, 14 de julho de 1998. Disponível em: <http://www1.folha.uol.com.br/fsp/especial/fj14079811.htm>. Acesso em: nov. 2016.

HORTA, Vera d'. MAM: Museu de Arte Moderna de São Paulo. Texto: Vera d'Horta; Fotografias: Romulo Fialdini e Bubby Costa, e dos Arquivos da Biblioteca do MAM e Fundação Bienal de São Paulo. São Paulo, SP: DBA Artes Gráficas, 1995.

IBRAM, Instituto Brasileiro de Museus. Guia dos Museus Brasileiros. Brasília: Instituto Brasileiro de Museus, Ministério da Cultura, 2011.

LIMA, P. G.; LESCHKO, N. M.; SEHN, T. C. M.; PEREIRA, L. P.; GONÇALVES, Y. P. Memória Gráfica de Pelotas: uma metodologia de análise. In: Anais do 10 P\&D Design - Congresso Brasileiro de Pesquisa e Desenvolvimento em Design. São Luís (MA): UFMA: 2226-2236, 2012.

LIMA, Paula Garcia; MICHELON, Francisca Ferreira. As peças gráficas do Parque Souza Soares (Pelotas, 1900-1930): algumas relações entre design e memória. In: Anais do 90 P\&D Design Congresso Brasileiro de Pesquisa e Desenvolvimento em Design. São Paulo: Anhembi Morumbi, 1206-1216, 2010.

MAC, Museu de Arte Contemporânea (São Paulo, SP). Catálogo geral das obras. São Paulo: Museu de Arte Contemporânea da Universidade de São Paulo, 1973.

MAM, Museu de Arte Moderna de São Paulo. Panorama de arte atual brasileira: pintura, 1970. [Texto] Paulo Mendes de Almeida. São Paulo: MAM, 60 p.; il. 1970.

. Panorama/84: arte sobre papel. [Textos] Aparício Basílio da Silva, Alberto Beuttenmüller. São Paulo: MAM, 1 v.; il., 1984.

. Guia de identidade visual MAM. São Paulo. Projeto gráfico Sinlogo, 2013.

. [Site]. Sem data. Disponível em: <http://mam.org.br/>. Acesso em: 26 nov. 2016.

MARGOLIN, Victor. Design na História. Tradução Marcello Montore. In: Revista Agitprop. Ano II, no 16 , 2009. Disponível em: <http://www.agitprop.com.br/index.cfm?pag=repertorio_det\&id=21\&titulo=repertorio>. Acesso em: 20 out. 2015.

MENESES, Ulpiano. B. de. Fontes visuais, cultura visual, história visual. Balanço provisório, propostas cautelares. In: Revista Brasileira de História, v. 23, no 45, p. 11-36, 2003.

MIOCQUE, Christine; WARRAK, Claudia. Identidade visual - Museu de Arte Moderna de São Paulo. [Manual] Arquivo digital [.pdf], Março, 2003.

MUSEU PAULISTA da Universidade de São Paulo. História do Museu Paulista. Sem data. Disponível em: <http://www.mp.usp.br/o-museu/historia-do-museu-paulista>. Acesso em: 16 out. 2016.

O MUSEU de Arte Contemporânea da Universidade de São Paulo. São Paulo, SP: Banco Safra, 1990.

PETIT, Francesc. A Marca do Catalão: o publicitário, designer e artista plástico Francesc Petit criou a identidade visual do Masp. In: Revista Masp: Museu de Arte de São Paulo. Ano 1, no 1. São Paulo: Carta Editorial, 1992.

REDE, Marcelo. História a partir das coisas: tendências recentes nos estudos de cultura material. 
Resenha de LUBAR, S.; KINGERY, D. W. (Ed.) History from things: essays on material culture. Washington: Smithsonian Institution Press, 1993. In: Anais do Museu Paulista. São Paulo. № Sér. V. 4, p. 265-282. Jan./Dez., 1996.

SIMÕES, Maria (ed.). MASP 60 anos: história em 3 tempos. São Paulo, SP: Museu de Arte de São Paulo: Mercedes Benz, 2008.

TWYMAN, Michael. A schema for the study of graphic language. In: Kolers, Paul; Wrolstad, Merald \& Bouma, Herman (Eds.). Processing of visible language. New York: Plenum Press, v.1, p. 117-150, 1979.

WILLE, D. N.; SOUZA, H. P.; SILVA, M. B. M.; FERREIRA, M. M. IGANSI, J. F. Análise Gráfica dos Anúncios "Elixir de Nogueira" publicados no "Almanach de Pelotas" de 1913 a 1918. In: Anais do 9o P\&D Design - Congresso Brasileiro de Pesquisa e Desenvolvimento em Design . São Paulo (SP): Anhembi Morumbi, 1593-1598, 2010.

WOLLNER, Alexandre. Alexandre Wollner: design visual 50 anos. São Paulo: Cosac Naify, 2003.

ZANINI, Walter. (Org.). História Geral da Arte no Brasil. Vol. 1 e 2. São Paulo: Instituto Walther Moreira Salles, 1983. 